\title{
Honoring the Legacy of Jackie Kirk
}

\author{
Fatima Khan, Claudia Mitchell, and Marni Sommer
}

\section{$\cos 80$}

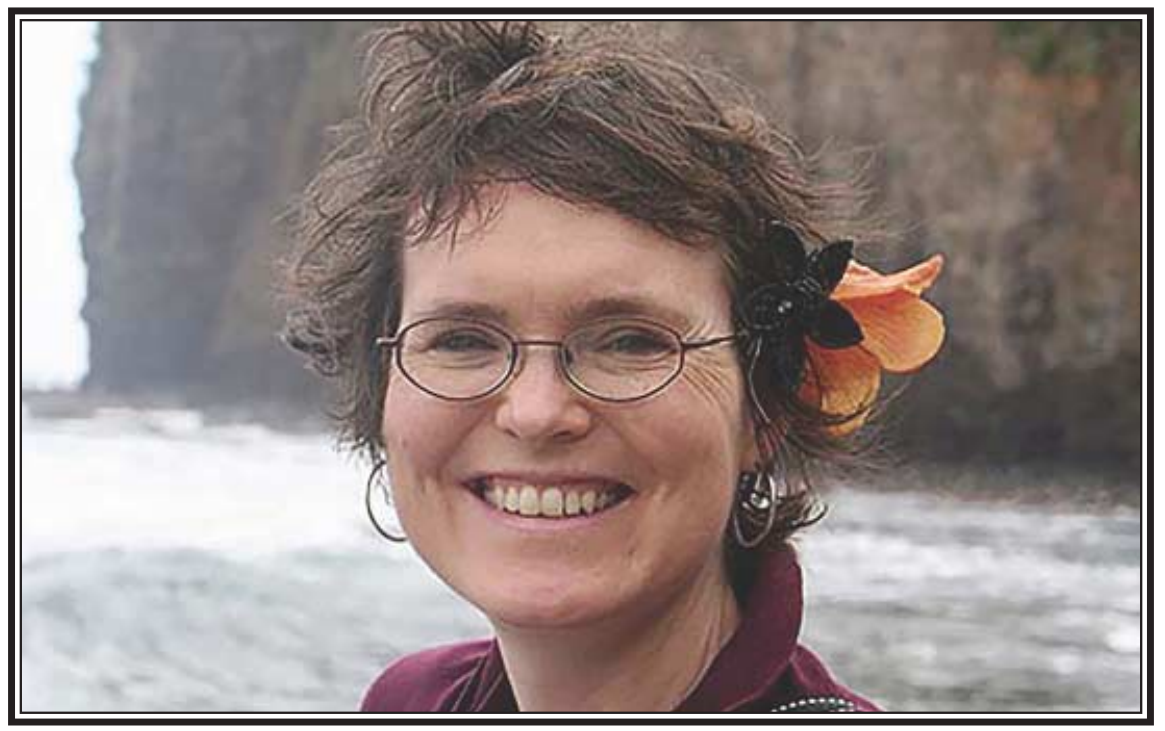

Figure 1. Jackie Kirk: Educator, activist, and trailblazer.

This year marks the tenth anniversary of the death of Jackie Kirk, a co-founder of Girlhood Studies: An Interdisciplinary Journal, and an incredibly effective member of the global education community who died at the hands of the Taliban in Afghanistan on 13 August 2008 while working on a project on girls' education. As an activist and researcher Jackie had a great range of expertise, including that of dealing with education in emergencies, the challenges facing women teachers, and the menstruation-related needs of school-going girls, as well as a grasp of the importance of visual images in understanding the realm of girls' education. She brought to her work an attention to critical theoretical concepts alongside the practical; she always placed girls and women (especially women teachers) at the center of her explorations, her analyses, and her recommendations for policy and practice. 
There are numerous events and initiatives taking place in 2018 in recognition of Jackie's important legacies. One of the key events, as we highlight here, was a double-session of the Gender and Education Committee at the annual conference of the Comparative and International Education Society (CIES) which took place in Mexico City, from March 25 to 29. The focus of this half-day event that brought together more than 70 researchers, activists, global education donors/funders, policymakers, and members of international NGOs, was to highlight the ways in which Jackie's work-her legacy — has evolved over the last decade while also identifying how her work can continue.

The half-day session was divided into two parts. The first, a panel chaired by Julia Dicum of Global Affairs Canada, was made up of five speakers, each representing a different facet of Jackie's work and coming out of different academic and policy arenas. Nora Fyles of the United Nations Girls' Education Initiative (UNGEI) spoke about women teachers, Relebohile Moletsane, University of KwaZulu-Natal about visual methodologies; and Karen Mundy from the Global Partnership for Education about girls' education and international partnerships. Marni Sommer from the Mailman School of Public Health, Columbia University, addressed the issue of menstrual hygiene management, and Rena Deitz of the International Rescue Committee (IRC) that of education in emergencies. Following this panel, the audience members

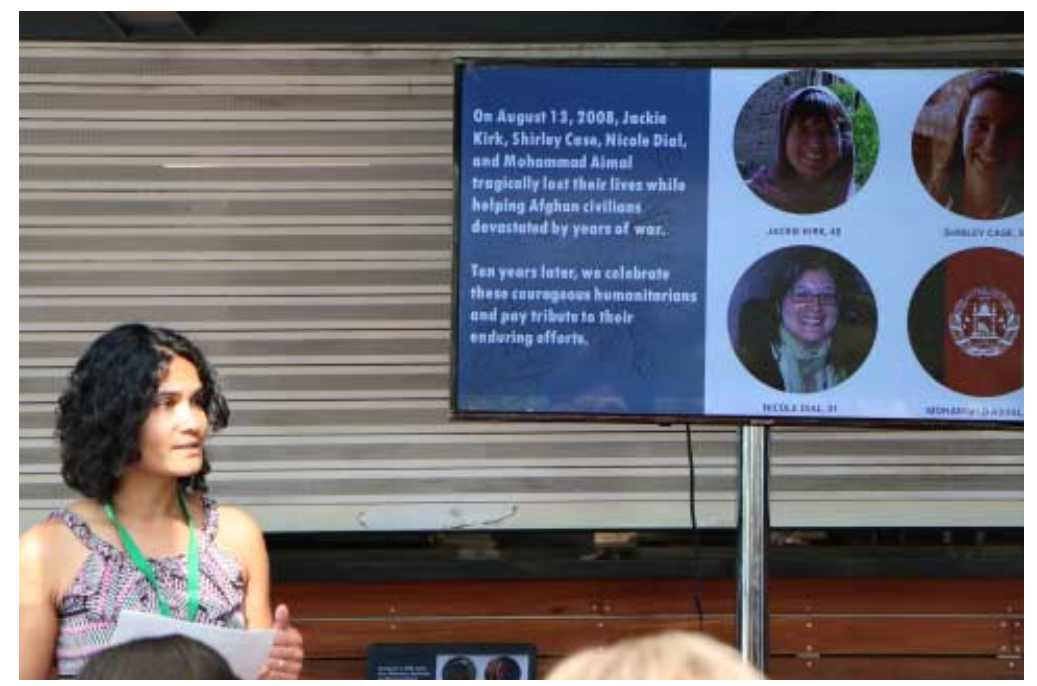

Figure 2. Payal Shah of the Gender and Education Symposium Committee welcoming participants. Photo by Milka Nyariro. 
Figure 3. The Honoring Jackie Kirk's Legacy panel (left to right): Marni Sommer, Relebohile Moletsane, Nora Fyles, Julia Dicum, Rena Deitz, and Karen Mundy. Photo by Milka Nyariro.

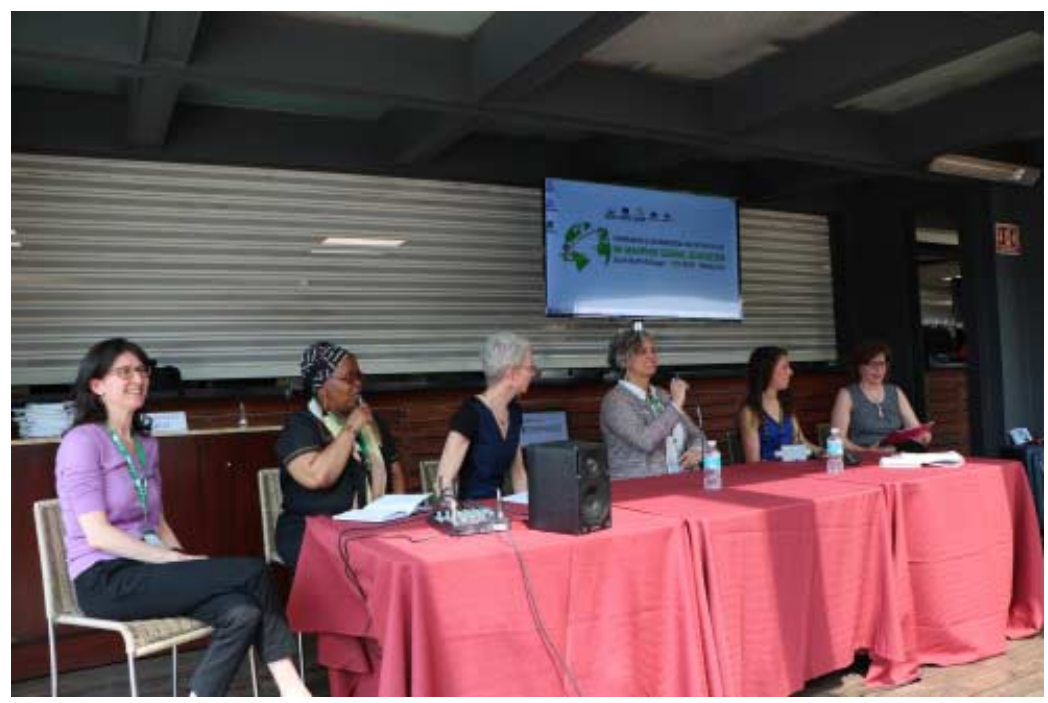

joined one of the various break-out groups that focused on key areas related to Jackie's work, each convened by a facilitator working in one of these areas. The facilitators included Karen Monkman (DePaul University); Cathryn Magno (University of Fribourg); Scott Walter (Canadian Organization for Development through Education); and Jackie Haver (Save the Children). Each group considered Jackie's contribution to research, activism, and policy work in its respective area, and discussed, too, how the area is developing and where it needs to go. These were indeed conversations about legacy.

It is difficult to capture in a few words the breadth and depth of the conversations, the passion of the speakers, and the commitment of participants in the break-out groups or give even a small sense of the range of Jackie's reach, so we invite readers to visit the Jackie Kirk memorial page on Berghahn Journals' Girlhood Studies homepage, created by the first author, or access some of the many writings that were produced about her following her death. (See Mundy and Dryden-Petersen 2012; Mitchell and Khan 2015; and Fiona Leach's 2010 guest editorial, "Negotiating, Constructing and Reconstructing Girlhoods" in a special issue of GHS dedicated to Jackie.) Taking into considerations her keen concern for the visual and her article on visual images written with Cathryn Magno and published after her (Jackie's) death (see Magno and Kirk 2010), we offer here a few snapshots of the event. 


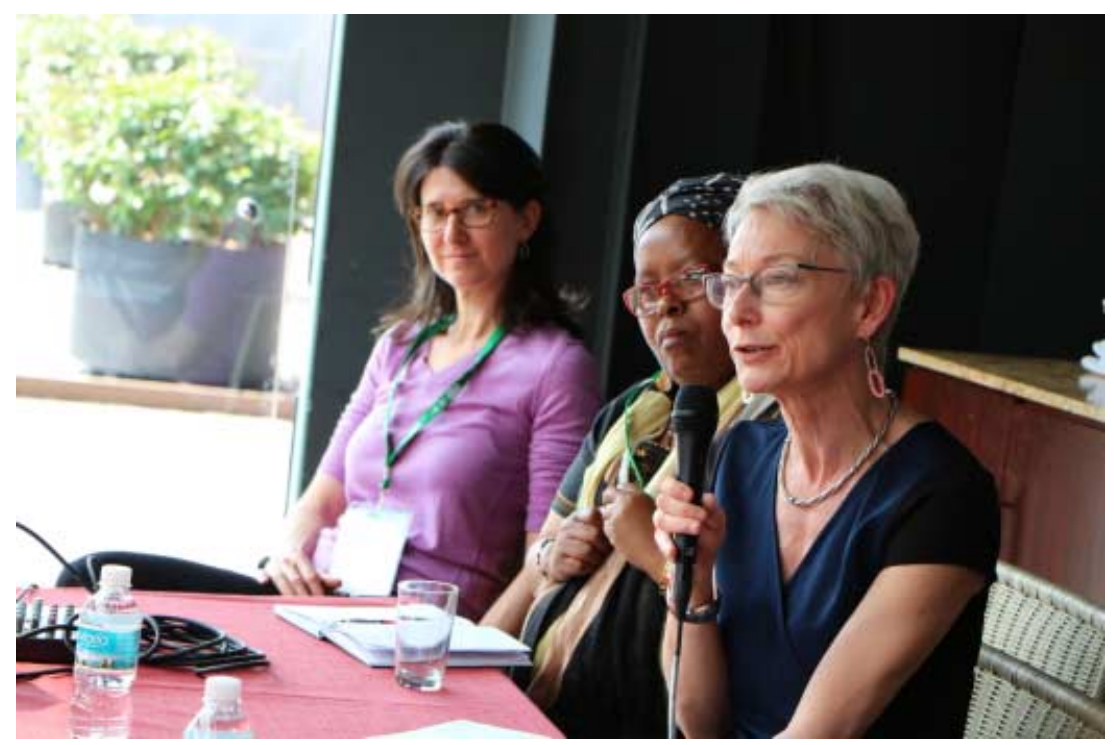

Figure 4. Nora Fyles (right) (United Nations Girls' Education Initiative) speaking at the panel alongside Marni Sommer (left) and Relebohile Moletsane. Photo by Milka Nyariro.

\section{A Teacher-centered Approach: Nora Fyles Remembers}

One of Jackie's most significant contributions was to shine a laser light on teachers and, in particular, teachers in the most challenging spaces [like] refugee settings and other situations of conflict and crisis. Jackie documented the experience of teachers, mostly women, [along with] their voices, and their lived realities. In her early writings on women teachers in Karachi, Jackie described the inherently contradictory experience of being a women teacher in Pakistan, an experience of agency and submission, of power and powerlessness, and the delicate balancing act of what is doable within quite rigid boundaries. Jackie also drew our attention to the gendered dynamics in the classroom and reminded us, drawing on the important work of Nelly Stromquist et al., that 'it is not possible to isolate girls' education from the substance and politics of women's concerns' (2000: 255). Moreover, gender equality work in teacher education cannot only focus on teaching strategies to encourage girls' participation, but must connect with teachers' own gender perspectives, concerns, experiences, and challenges. Jackie went on to do important work on healing classrooms 
with Rebecca Winthrop and other IRC colleagues. She called for us to focus on teacher development and support, based on who teachers are, including their strengths and challenges. The Creating Healing Classrooms manual remains a valuable resource for teachers and teacher trainers, using what Jackie called a 'teacher-centered approach.'

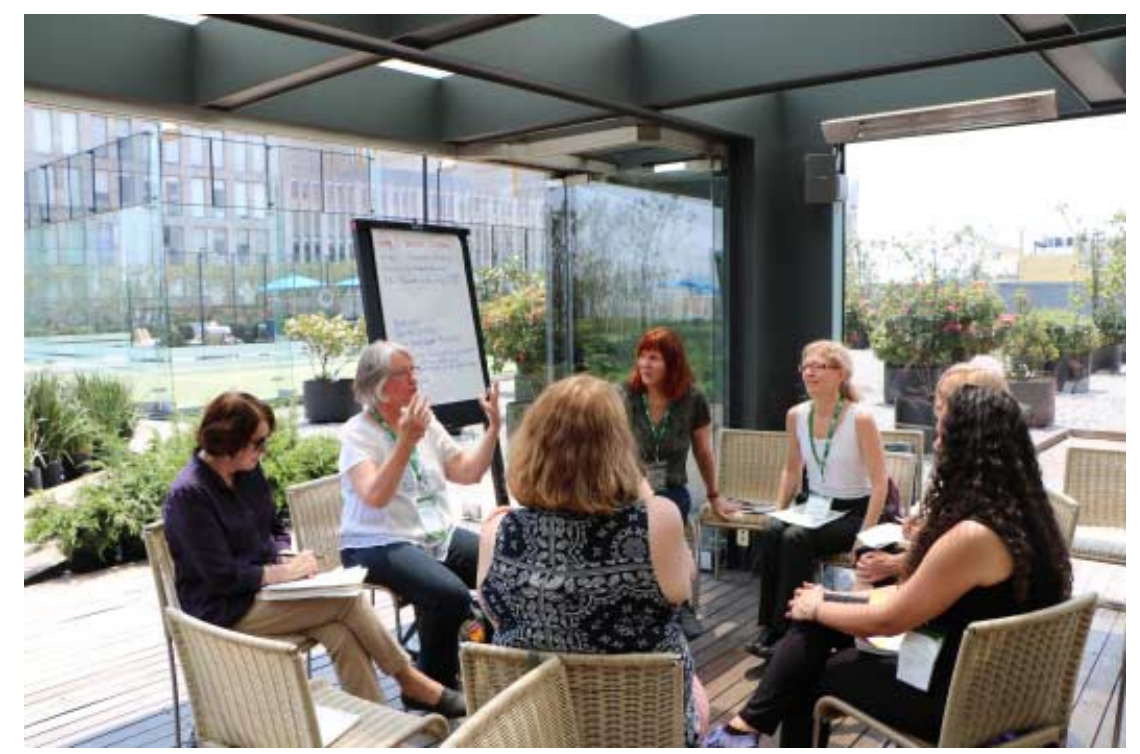

Figure 5. Break-out group on women teachers led by Karen Monkman (second from left). Photo by Fatima Khan.

Figure 6. Break-out session highlighting and reflecting on the issues present in Education in Emergencies. Photo by Milka Nyariro.

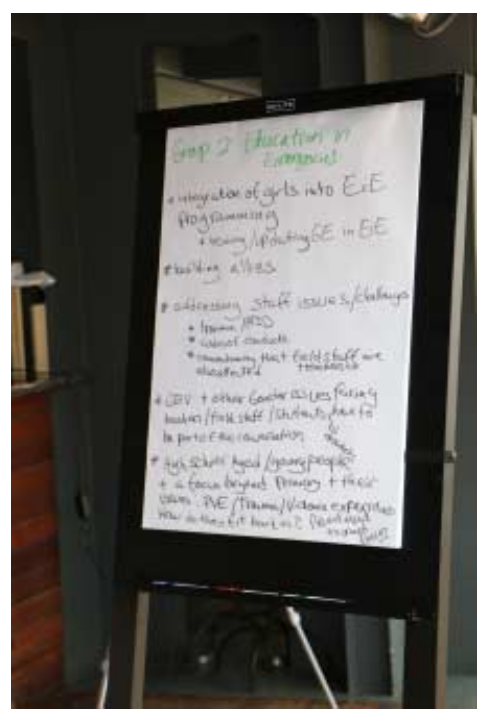




\section{Critical Activist Practices: Casey Burkholder Reflects}

The Jackie Kirk event at CIES highlighted many of her research and humanitarian interests_-girls' rights, menstruation, and participatory visual methodologies. The event honored Jackie's legacy in engaging with a panel and following up with break-out sessions on issues ranging from visual research ethics to sexual health and barriers to schooling for girls around the globe. As the recipient of the Jackie Kirk Fieldwork Award at McGill in 2015, I was thankful to have had the opportunity to build my own research agenda on Jackie's excellent example. I was honored to have been able to learn more about the critical activist practices and legacies that have continued the work that Jackie began.

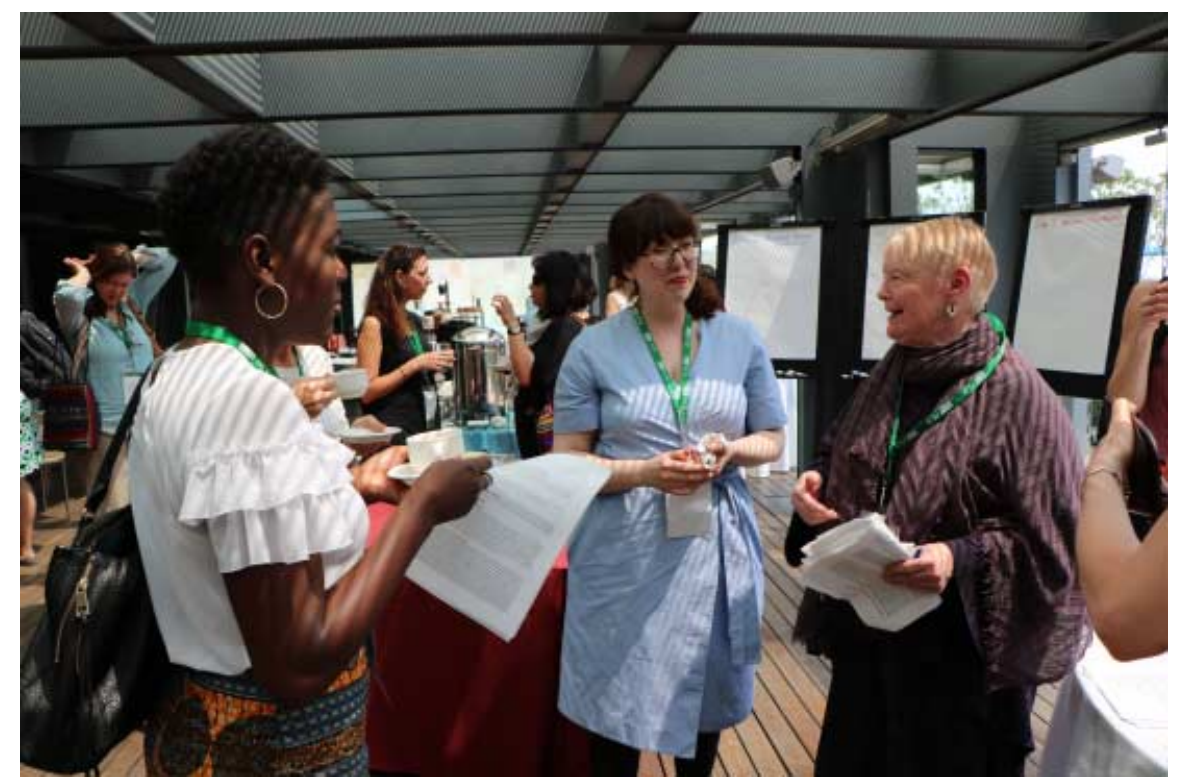

Figure 7. Noella Binda (left) in conversation with Casey Burkholder and Claudia Mitchell (right). Photo by Milka Nyariro. 


\section{Gift of Leadership: Scott Walter Reflects}

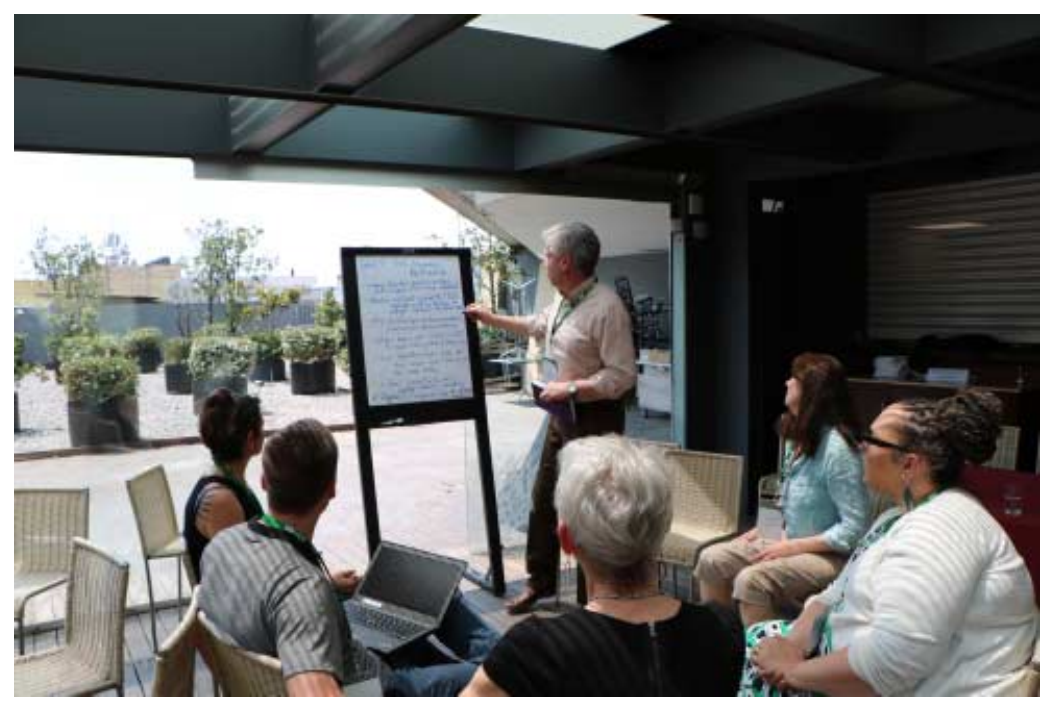

Figure 8. Scott Walter (standing) leading a break-out session on girls' education and partnerships. Photo by Fatima Khan.

It was quite incredible to be part of an event during which speaker after speaker from around the world spoke to the outsize influence Jackie had had on their work and on their lives, often referring to the experience as if it had been only yesterday. My own experience with this amazing woman was through her work as a passionate member of the international network for education in emergencies when I was the policy head for education at CIDA (now Global Affairs Canada). Later, back in the NGO world and looking for sage and thoughtful advice on programming in Liberia and Sierra Leone, the best I received was from Jackie who seemed to understand instinctively how to work together with stakeholders and achieve positive results, even in such deeply scarred countries. A similar request to advise on education programming in Afghanistan was met with her usual business-like efficiency and a seemingly endless willingness to support something she cared deeply about. And while her brutal murder may have ended her all too short life, her gift of leadership is clearly as strong and meaningful as ever. 


\section{Jackie Kirk Fellowship Recipients}

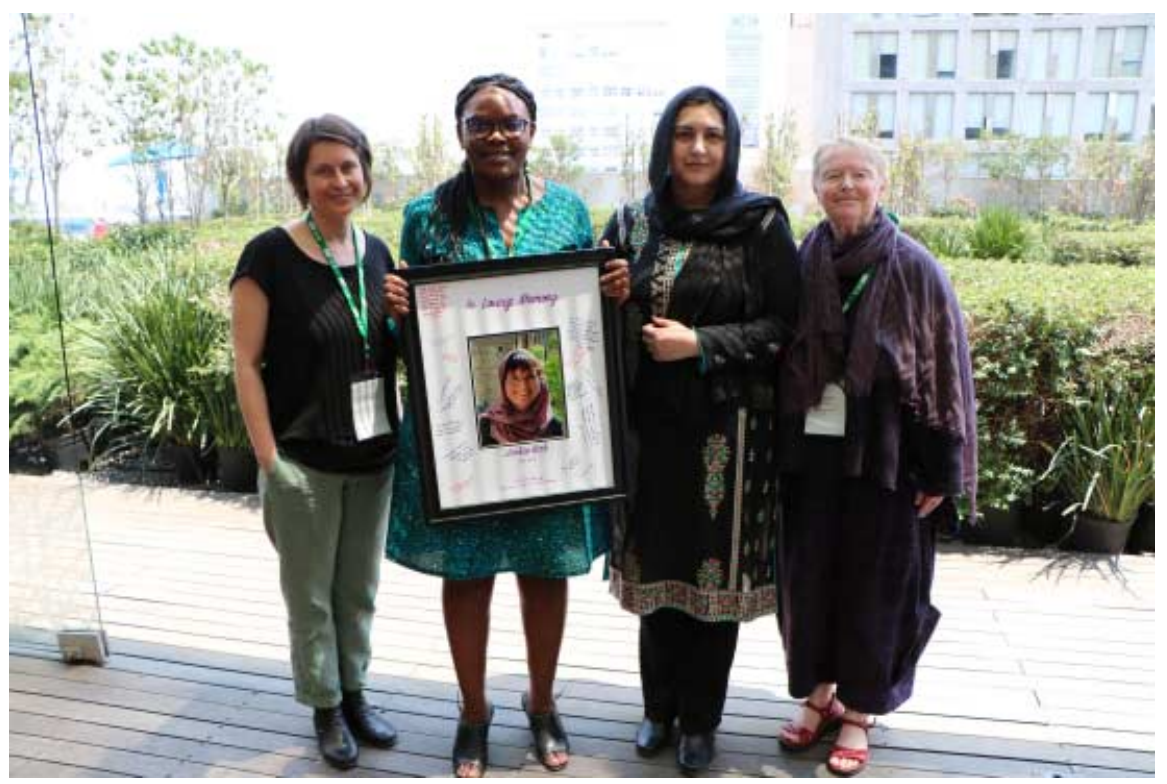

Figure 9. Former recipients of the Jackie Kirk Fellowship (McGill University) with a portrait of Jackie (left to right): Jennifer Thompson, Milka Nyariro, and Fatima Khan (with Claudia Mitchell). Photo by Bettina Dembek.

\section{Commemorative Memorials}
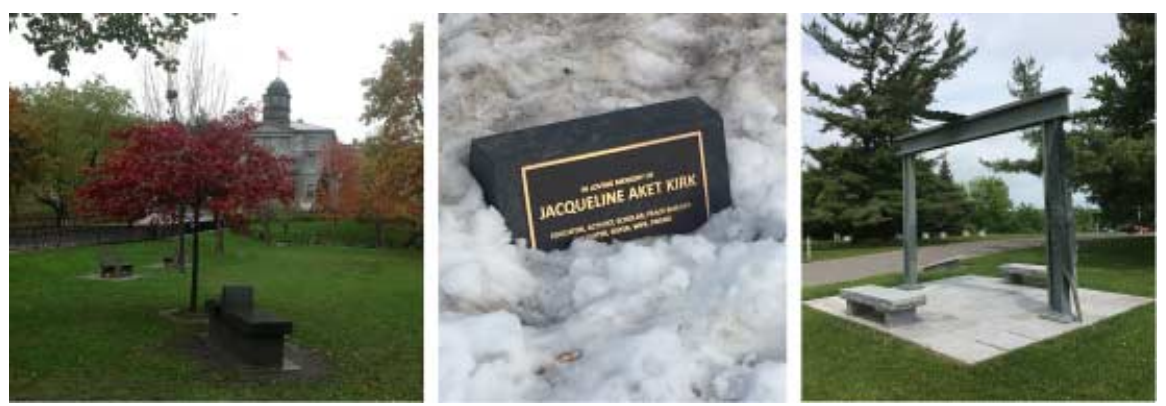

Figure 10. Memorials commemorating Jackie and the efforts of humanitarian aid workers: McGill University, Montreal, Canada (left and center); Ottawa, Ontario, Canada (right). Photos by Sadaf Farookhi (center), Fatima Khan (left and right). 


\section{Are There Two Jackie Kirk's? Catherine Vanner Reflects}

While academia is known to be cut-throat and competitive, we have heard how powerful friendship and collaboration can be in creating productive partnerships. Panelist Marni Sommer from Columbia University spoke about how she had thought she had had a unique relationship with Jackie, but the realization for all of us that Jackie fostered close relationships with many collaborators made her even more special. She showed that relationships are essential to partnership and that through the strength of friends working together, joy as well as productivity emerges. We have also learned about the value of pursuing our passions, even, or especially, when they take us in all directions. Conventional wisdom in academia is to focus so that we can to develop our area of expertise. But Jackie's work spilled over beyond conventional borders, and she let her boundless energy and enthusiasm be her guide. Panelist Rena Deitz from the IRC recollected how a colleague commented to her, 'Isn't it amazing that there are two Jackie Kirks who are both so prolific?' In fact, there was only one Jackie Kirk who illustrated the importance of working hard to pursue what you believe is important, instead of being restricted to a given area. Losing Jackie was a monumental tragedy for those who knew and loved her, as well as for those who would never get the chance to know her. By bringing together her friends and colleagues, we have all had the chance to be inspired not only by her work but also by her spirit. For new scholars and practitioners in gender and education, this means encouragement to be guided by conviction, determination, and friendship. We have learned that when you combine these principles with hard work, the possibilities are endless.

Figure 11.

Catherine Vanner

(sitting, left) in a break-out session on menstrual hygiene management led by Jackie Haver (standing). Photo by Fatima Khan.

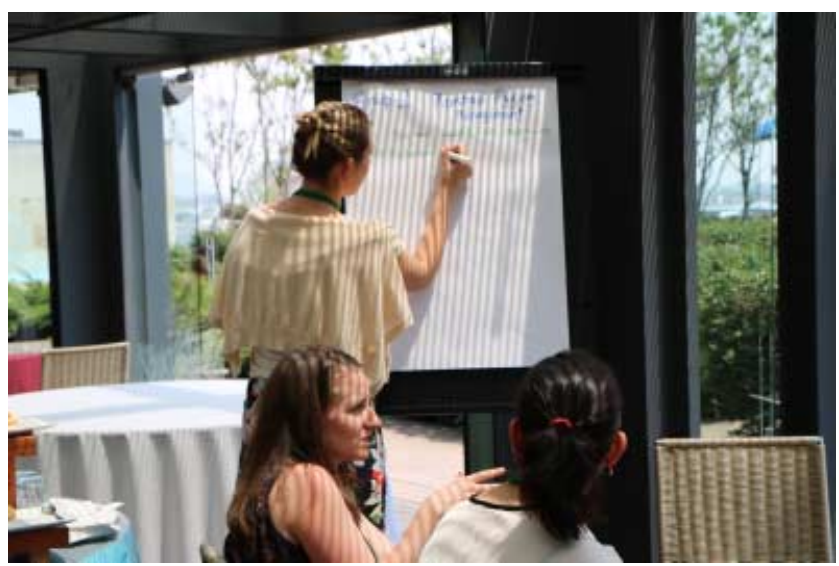




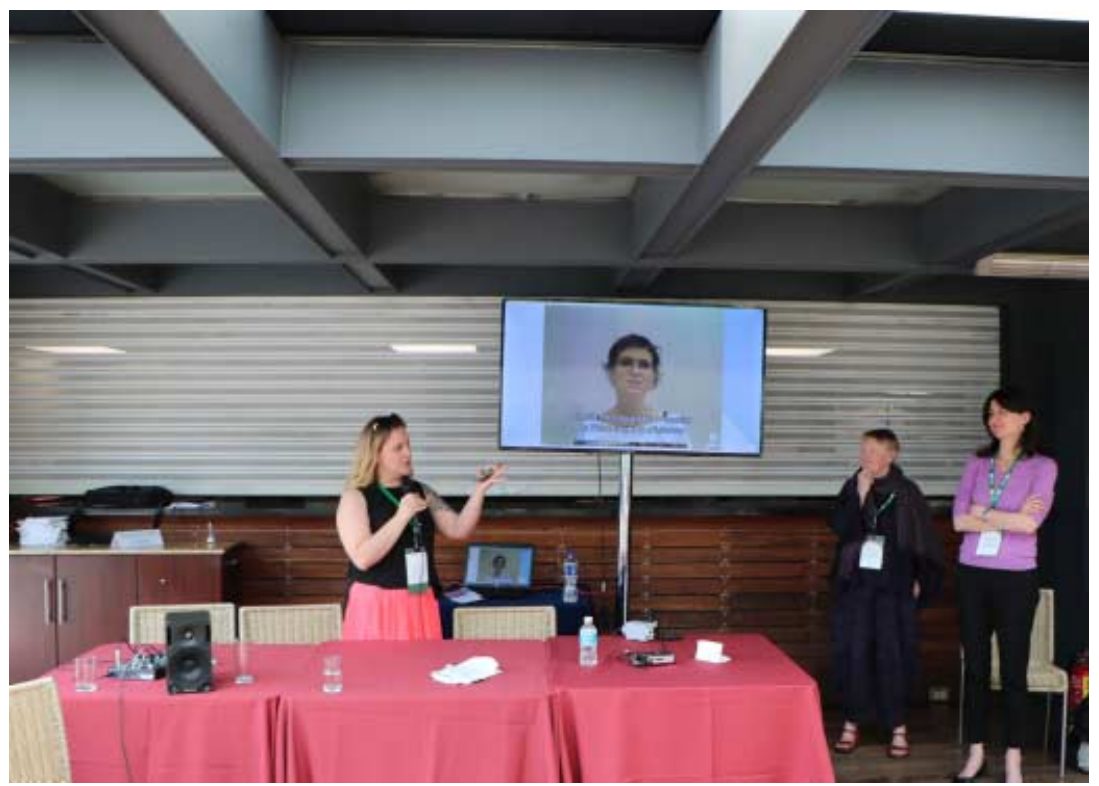

Figure 12. Emily Anderson, co-chair of Gender and Education Symposium Committee, providing some closing remarks (Claudia Mitchell and Marni Sommer looking on). Photo by Milka Nyariro.

\section{A Photo Matte in Loving Memory}
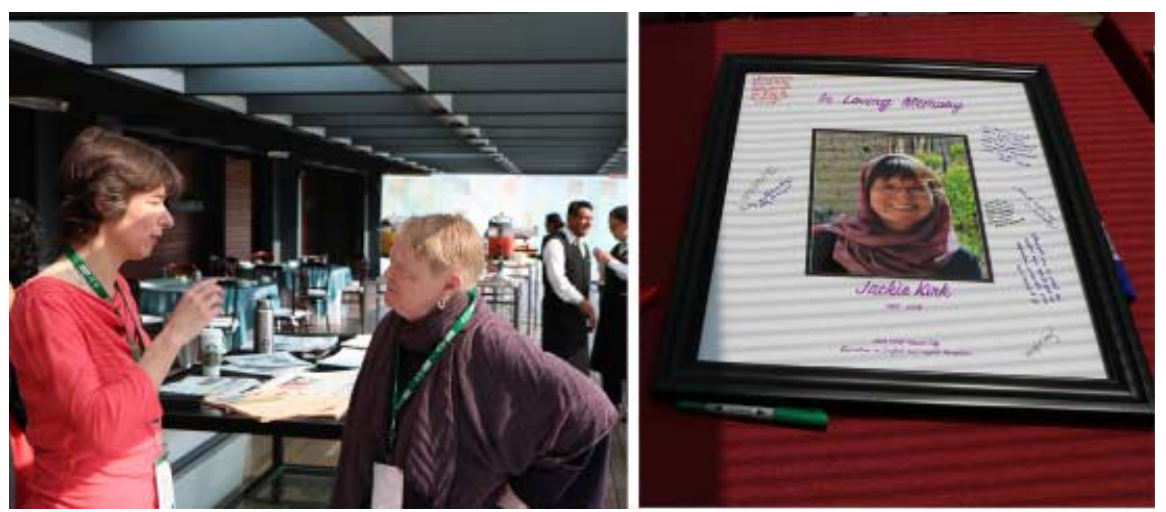

Figure 13. Bettina Dembek (left) in conversation with Claudia and the Jackie Kirk Tribute Matte. Photos by Milka Nyrariro (left) and Fatima Khan (right). 
As a thoughtful and lasting tribute to Jackie, Bettina Dembek (Education Development Center), created a beautiful photo matte that was signed by attendees of not only the double-session, but also the Education in Crisis and Conflict Reception, hosted by the Education in Crisis and Conflict Network (ECCN) and its partners. Guests of both events added their own personal tributes. The photo matte has been sent to Jackie's parents in recognition that she remains an inspiration for many around the world.

\section{"We're Not Finished Yet"}

Even as we remember the tears, the laughter, and the constant reiteration of "How could it have been ten years ago?" and our sense of how remarkable this event was, in reaching and bringing together so many networks into one room ten years later, we know that we cannot capture it all. Echoing throughout the session was the recognition that everyone in the room, whether they had met Jackie or not, knew that, as she said, she stood for what we might think of as a key ethical slogan: "We're not finished yet."

\section{Acknowledgments}

We are grateful to the CIES Gender and Education Symposium Committee for all their support, including sponsoring a lunch, and to all the speakers and break-out group facilitators who so enthusiastically responded to the invitation to participate. We are very grateful to Milka Nyariro for heading up the visual documentation of the event.

FATIMA KHAN is a doctoral candidate at McGill University, in exploring children's well-being in conflict zones, examines curatorial practices that emerge from conditions of adversity and issues that arise in the exhibiting of children's drawings. E-mail: fatima.khan2@mail.mcgill.ca

Claudia Mitchell is a James McGill Professor at McGill University, Canada, and an Honorary Professor at the University of KwaZulu-Natal, South Africa. Her current research focuses on girl-led approaches to addressing sexual violence. E-mail: claudia.mitchell@mcgill.ca 
Marni Sommer, Mailman School of Public Health, Columbia University, in conducting participatory research with young people in low-income countries, explores transitions through puberty and adolescence and develops puberty books in partnership with national governments. E-mail: marni.sommer@columbia.edu

\section{References}

Leach, Fiona. 2010. "Negotiating, Constructing and Reconstructing Girlhoods." Girlhood Studies: An Interdisciplinary Journal 3 (1): 3-8. https://doi.org/ 10.3167/ghs.2010.030102

Magno, Cathryn, and Jackie Kirk. 2010. "Sight Unseen: Re-viewing Images of Girls' Education." Girlhood Studies: An Interdisciplinary Journal 3 (1): 9-33. https://doi.org/10.3167/ghs.2010.030103

Mitchell, Claudia, and Fatima Khan. 2015. "Jackie and Me, Jackie and Us: Productive Entanglements and Learning Conversations in the Supervision Process." In Polyvocal Professional Learning through Self-Study Research, ed. Kathleen Pithouse-Morgan and Anastasia P. Samaras, 75-91. Rotterdam. Sense.

Mundy, Karen, and Sarah Dryden-Petersen, eds. 2015. Educating Children in Conflict Zones: Research, Policy, and Practice for Systemic Change-A Tribute to Jackie Kirk. New York: Teachers College Press.

Stromquist, Nelly P., Steven J. Klees, and Shirley J. Miske. 2000. "USAID Efforts to Expand and Improve Girls' Primary Education in Guatemala." In Distant Alliances: Promoting Education for Girls and Women in Latin America, ed. Regina Cortina and Nelly P. Stromquist, 239-260. New York: RoutledgeFalmer. 